\section{An Unusual Complication \\ Following Intubation of a Benign Oesophageal Stricture}

Stenting of benign oesophageal strictures is feasible, but we are unclear as to the potential for complications in the long term, especially following distal stent migration. We report a fatal complication which occurred many years after placement that argues for the retrieval of all dislodged stents.

A 91-year-old gentleman presented to hospital with clinical evidence of lifethreatening small bowel obstruction. He had had an Atkinson tube inserted 8 years previously to treat a recurring distal oesophageal stricture. (At that time, due to coexisting cardiopulmonary compromise, he was deemed unfit for surgical intervention.) The stent had migrated to the stomach within the first year of placement. As subsequent attempts at endoscopic removal failed, a policy of "watchful waiting" was adopted.

On admission, supine radiography of his abdomen demonstrated ileal obstruction secondary to migration of his oesophageal stent with impaction at the ileocaecal valve (Figure 1). The stent, which had become obstructed by a food bolus, was removed under regional anaesthesia. The patient succumbed to respiratory complications 5 days later.

In patients who are unfit for surgery, benign oesophageal strictures are managed with proton pump inhibitors and oesophageal dilation. Should these measures fail, oesophageal intubation is a potential option $[1,2]$. Distal stent migration frequently occurs however, and attempts to retrieve the prosthesis endoscopically often fail [1, 3]. This case demonstrates that a stent can pass distally via a normal gastrointestinal tract into the small bowel with fatal consequences. It is reasonable to conclude that oesophageal stents that migrate to the stomach should be retrieved electively to avoid such a complication, and that due consideration be given to operative retrieval via gastrotomy if endoscopic measures fail.

C. Power ${ }^{1}$, M. Rynne ${ }^{2}$, T. O'Gorman ${ }^{2}$,

D. Maguire ${ }^{1}$, O. J. McAnena ${ }^{1}$

${ }^{1}$ Dept. of Surgery, University College

Hospital, Galway, Ireland

${ }^{2}$ Dept. of Medicine, University College

Hospital, Galway, Ireland

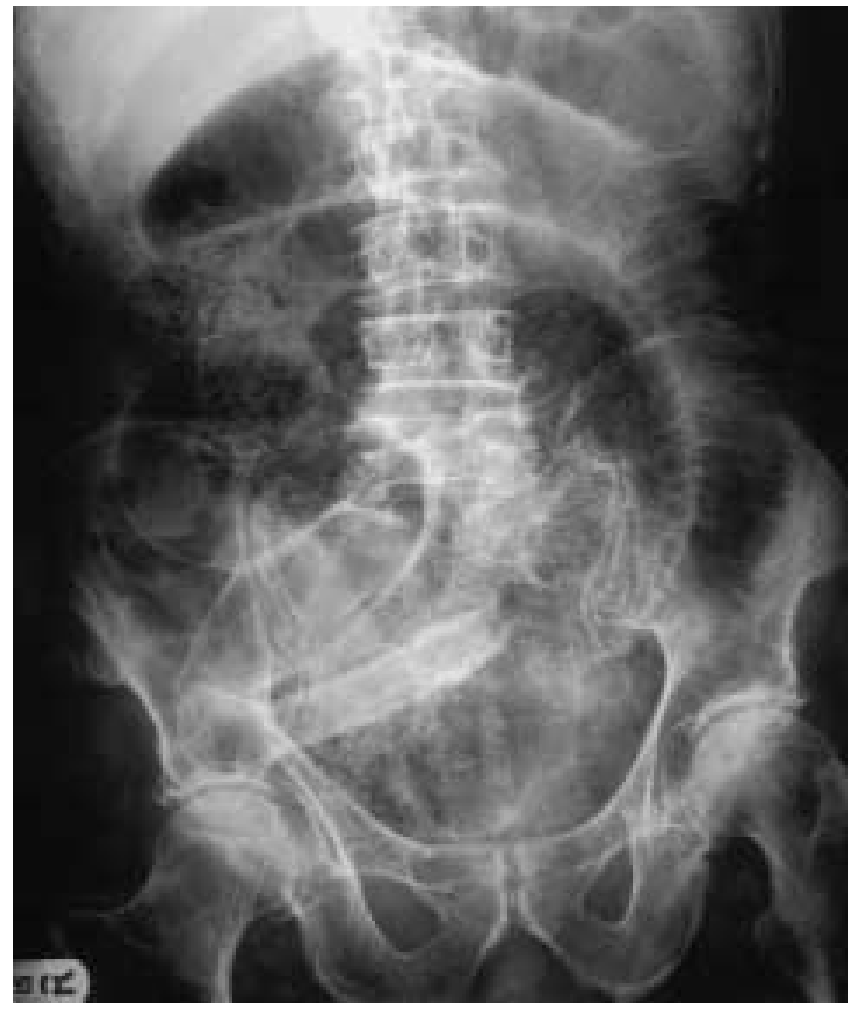

Figure 1 Supine abdominal radiograph demonstrating mechanical ileus secondary to an oesophageal stent in the distal ileum

\section{References}

${ }^{1}$ Song HY, Park SI, Do YS, et al. Expandable metallic stent placement in patients with benign esophageal strictures: results of long-term follow-up. Radiology 1997; 203: 131-136

${ }^{2}$ Foster DR. Self-expandable oesophageal stents in the management of benign peptic oesophageal strictures in the elderly. Br J Clin Pract 1997; 51: 199

${ }^{3}$ Hramiec JE, O'Shea MA, Quinlan RM. Expandable metallic esophageal stents in benign disease: a cause for concern. Surg Laparosc Endosc 1998; 8: 40-43
Corresponding Author

C. Power, MMSc, FRCSI

Dept. of Academic Surgery

Cork University Hospital

Wilton

Cork

Ireland

Fax: $\quad+353-21-4344230$

E-mail: cjppower@yahoo.com 